\title{
Barriers and Facilitators to Clinical Decision Support Systems Adoption: A Systematic Review
}

\author{
Srikant Devaraj ${ }^{1}$, Sushil K. Sharma ${ }^{1}$, Dyan J. Fausto ${ }^{2}$, Sara Viernes ${ }^{3} \&$ Hadi Kharrazi $^{4}$ \\ ${ }^{1}$ Ball State University, USA \\ ${ }^{2}$ Ascension Information Services, USA \\ ${ }^{3}$ ADA SCDI Working Group Member, USA \\ ${ }^{4}$ Johns Hopkins School of Public Health, USA \\ Correspondence: Srikant Devaraj, Center for Business and Economic Research, Ball State University, USA. Tel: \\ 1-765-285-4304. E-mail: sdevaraj@bsu.edu
}

Received: June 28, 2014

Accepted: July 21, $2014 \quad$ Online Published: July 24, 2014

doi:10.5430/jbar.v3n2p36

URL: http://dx.doi.org/10.5430/jbar.v3n2p36

\begin{abstract}
The objective of the study was to identify potential barriers and facilitators to improve clinical practice using computer-based Clinical Decision Support System (CDSS). Studies published since 2000 were found using PubMed database, PsychInfo, CINAHL, EBSCOhost database, and Google scholar. Twenty-six relevant publications were examined. Thirty-five unique barriers and twenty-five unique facilitators were identified in the literature as important determinants of CDSS's adoption in clinical practice. The list of barriers and facilitators collected from each study were then organized under the four dimensions of The Unified Theory of Acceptance and Use of Technology (UTAUT) model: performance expectancy, effort expectancy, social influence, and facilitating conditions. Some of the important barriers to CDSS use include; lack of time or time constraints, economic constraints (e.g., finance and resources), lack of knowledge of system or content, reluctance to use system in front of patients, obscure workflow issues, less authenticity or reliability of information, lack of agreement with the system, and physician or user attitude toward the system. The study contributes immensely to the literature by identifying the important barriers and facilitators of CDSS.
\end{abstract}

Keywords: Decision support system, IT adoption, Clinical decision support system, UTAUT model, Barriers and facilitators

\section{Introduction}

Information technology has become increasingly prevalent in all industries, especially in the healthcare arena. Recent decades have exhibited the development of a wide variety of information systems employed to aid clinicians in decision making. One such system is the computer-based Clinical Decision Support System (CDSS) developed to provide patient-specific, evidence-based advice in order to overcome some of the challenges facing the healthcare industry, such as diagnosing health problems, medication-prescribing effectiveness, and reducing medical errors, to name a few (Varonen, Kortteisto \& Kaila, 2008). Despite convincing evidence for the effectiveness of CDSSs in medicine, they are, nevertheless, rarely used in clinical practice. Understanding the reasons behind this fact could be of help in finding tools that facilitate [its] further dissemination (Toth-Pal, Wardh, Strender \& Nilsson, 2008). The aim of this paper is to identify the potential barriers and facilitators which hinder or enable CDSS use in clinical settings. Recognizing these factors will give management, along with Information Technology (IT) decision makers, a framework to successful CDSS implementation and use, enabling them to focus on specific factors which ensure definite outcomes.

In order to provide well-defined constructs and fully exploit the findings of this paper, the Unified Theory of Acceptance and Use of Technology (UTAUT) model was used to categorize the various barriers and facilitators to CDSS adoption. This model was developed through a review of eight theories or models which were found by earlier research on user acceptance: theory of reasoned action, the technology acceptance model, the motivational model, the theory of planned behavior, a model combining the technology acceptance model and the theory of planned behavior, the model of PC utilization, the innovation diffusion theory, and the social cognitive theory (Venkatesh et al.). This model was validated and found to explain 70 percent of the variance in intention. According to Venkatesh, 
the "UTAUT [model] provides a useful tool for managers needing to assess the likelihood of success for new technology introductions and helps them understand the drivers of acceptance in order to proactively design interventions (including training, marketing, etc.) targeted at populations of users that may be less inclined to adopt and use new systems."

The paper is organized in four sections. Section two is devoted to explain the methodology that we adopted to complete the study. The methodology section is followed by the section three on findings which identifies all the important barriers and facilitators to CDSS that emerged from these studies. The section four on discussion and summary presents CDSS acceptance models in UTAUT framework along with their barriers and facilitators. The last section concludes the discussion.

\section{Methodology}

\subsection{Search Strategy}

An extensive search of literature was performed with PubMed database, PsychInfo, CINAHL, EBSCOhost database and the first 100 articles of Google Scholar. Additionally, the reference lists of some included articles in Implementation Science were examined for other relevant references. The review was restricted to studies published since 2000. The keywords ((CDSS OR Clinical Decision Support systems) AND (barrier OR facilitator)) were used to identify CDSS's barriers and facilitators in improving clinical practice.

The title and abstract of each article was reviewed for relevance to the study aims. If there was any suggestion of relevant information, which met the following inclusion-exclusion criteria, the full text was retrieved and used in our study:

1) Is CDSS used in clinical context? (OK) or (NO)

2) Are the demographics, providers - clinicians? (OK) or consumers - patients? (NO)

3) Are the barriers and facilitators measured? (OK) or (NO)

4) Is the paper an original quantitative research? (OK) or a qualitative research and/or review, editorial, book chapter, etc.? (NO)

\subsection{Eligibility Studies and Data Extraction}

A search for the keywords in these databases produced 260 references, which reduced to 253 when the search was limited to publications after the year 2000 and duplicates were removed across all databases. The breakdown of references included 41 articles from PubMed,1 study from PsychINFO,25 papers from EBSCOHost,86 articles referenced from Implementation Science, and the first 100 articles of Google Scholar. For each study, the title of the paper, the APA citation, and the abstract were extracted and placed in a spreadsheet. The titles and abstracts of these studies were independently analyzed against the four inclusion-exclusion criteria (IEC) by the authors. The authors were advised to code "QQ" for further discussion if they were unable to reach a conclusion for any IEC's. We then counted the number of OK's in IEC's written by all authors for each study.

Out of 248 papers, there were four papers which had an OK count of 12 out of 12 that all the authors agreed to. Fourteen papers had an OK score of 11 (i.e., one author did not agree on 1 of the IEC) and 29 articles had an OK score of 10, implying that one or two authors disagreed to one or two IEC's. All other articles, which did not clearly meet the inclusion-exclusion criteria and with an OK score of less than 10, were excluded at this stage. The four papers with OK score of 12 were directly taken into our pre-final list of potential studies. After critically discussing the papers with an OK score of 10 and 11, the authors agreed to include 31 articles in the pre-final list, of which the abstract of 14 papers did not contain enough information to reach consensus among the authors.

After acquiring these 35 studies, and reviewing them critically, 26 publications were identified as relevant to our study objective. The authors then developed a coding sheet to list the important parameters for each study including the goal of the research, target population, methodology, results, conclusions, study limitations, and the barriers and facilitators.

\subsection{Organization into Themes}

Each of the unique barriers and facilitators were listed individually with the supporting studies next to them. The authors then categorized these barriers and facilitators under the four dimensions of Unified Theory of Acceptance and Use of Technology (UTAUT) model: performance expectancy, effort expectancy, social influence, and facilitating conditions. Figure 1 shows the systematic review process performed for this study. 


\section{Relevant Articles identified $=260$}

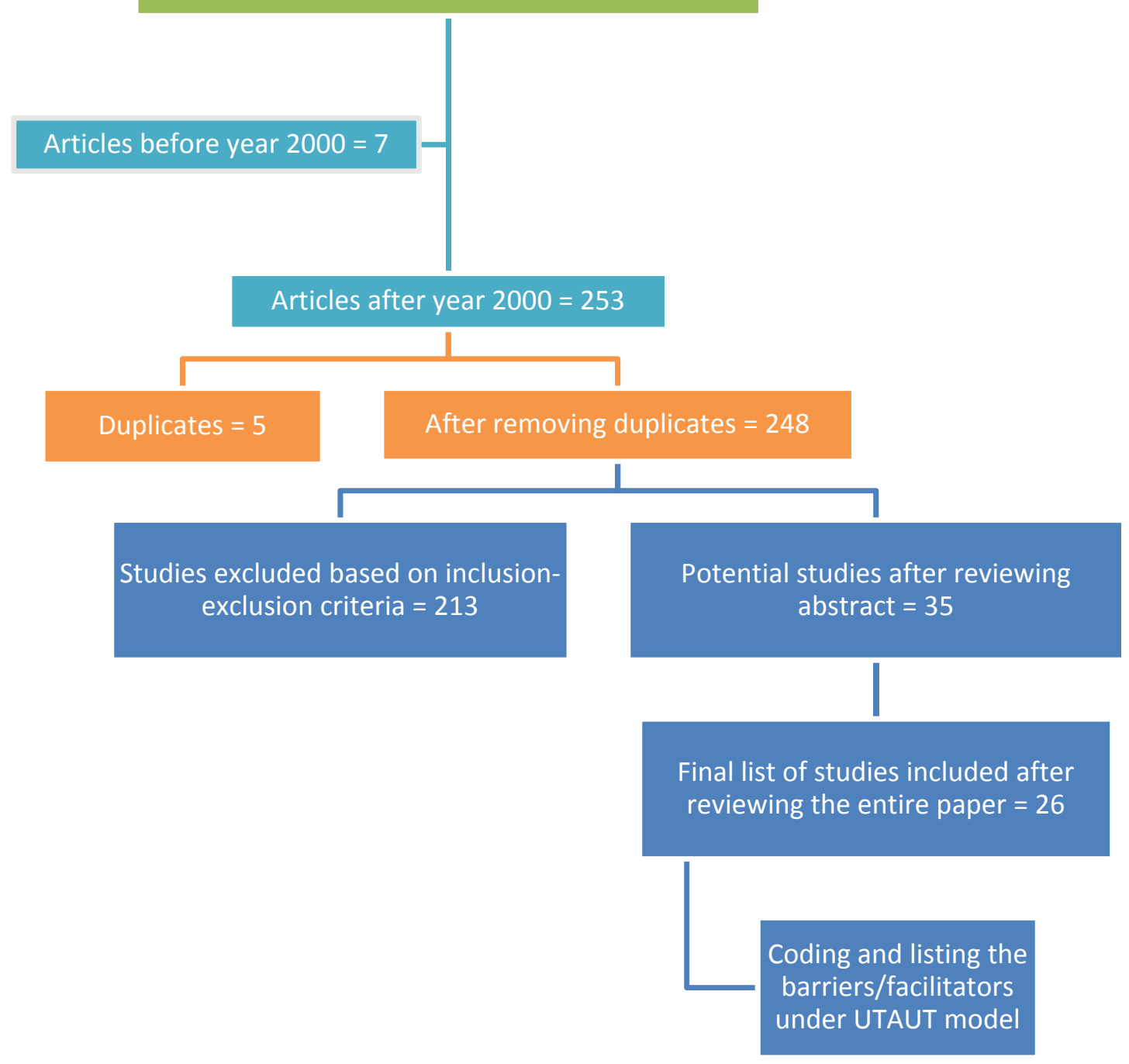

Figure 1. Systematic review process

\section{Findings}

The list of barriers and facilitators collected from each study was organized under the four determinants of user acceptance and usage behaviors, according to the UTAUT model. After reviewing the UTAUT model, each individual facilitator or barrier was then categorized within the determinants of performance expectancy, effort expectancy, social influence, and facilitating conditions.

\subsection{Performance Expectancy}

The UTAUT model defines performance expectancy as "the degree to which an individual believes that using the system will help him or her to attain gains in job performance" (Venkatesh, Morris, Davis \& Davis, 2003). Performance expectancy also includes how the individual perceives the system to be useful, as well as extrinsic motivators, such as how the system will improve outcomes, job-fit, or how the system improves the individual's performance, relative advantage, or use of innovation is better than the precursor, and outcome expectation. It is noted as the strongest predictor of intention. 


\subsubsection{Performance Expectancy Barriers to CDSS Adoption in Clinical Practice}

Seven identifiable barriers were determined throughout the 25 papers included in the review. The most prevalent barrier cited was the practitioner's lack of time or time constraints to use the CDSS. This particular barrier was found in eight different studies as having impact on the clinician's decision to use the system within the practice. Trafton et al. (2010), in an evaluation of acceptability and usability of DSS in opioid use for pain treatment in non-cancer patients, noted the lack of time as a significant barrier to the usability of the system. In addition to Trafton et al. (2010), the following studies cited time constraints as a serious impediment to the implementation of the system: Macy, Skelly, Shiffman \& Flynn (2005), in a study of the adherence of tobacco use treatment guidelines; Toth-Pal, Wardh, Strender \& Nilsson (2008), in a qualitative analysis of attitudes of general practitioners in using a CDSS; Peek et al. (2011), in their study of CDSS in cardiac rehabilitation; Subramanian et al. (2007), in a study of physician order entry in long term care facilities; Robertson et al. (2011), studying clinical decision support in prescribing practices in general practice; Harrisonet al. (2009), in a study of implementing patient decision support systems; and Murrayet al. (2009), in a study of the failure of CDSS to improve the outcomes of patients with hypertension. Time constraints included the extra time needed in accessing the CDSS, reading through system suggestions, and implementing the system in practice.

Trafton et al. (2010) and Demakis et al. (2000), who studied improving residents' compliance with standards of ambulatory care in a VA hospital setting, also pointed out the difficulty of competing clinical demands within the practice acted as a barrier to the use of CDSS. Varonen et al. (2008), in a study group of physicians on implementing CDSSs; Robertson et al. (2011); Hor et al. (2010), in a study of the attitudes and preparedness towards clinical decision support in e-Prescribing; and Lai, Macmillan, Daudelin \& Kent (2006), in their study of the potential of training to increase acceptance and use of CDSS for medical diagnosis; all noted that obscure workflow issues and the ability to incorporate the system within the normal flow of practice acted as barriers to clinician use. Several of the same papers, such as Varonen, Korttesito \& Kaila (2008); Robertson et al. (2011); Hor et al. (2010), in a study of the attitudes and preparedness towards clinical decision support in e-Prescribing; and Lai, Macmillan, Daudelin, \& Kent (2006) noted that authenticity and reliability of system information. Varonen, Korttesito \& Kaila (2008) and Hor et al. (2010) agreed the interoperability and standards in the system acted as a barrier to use. Peek et al. (2011); Lai, Macmillan, Daudelin \& Kent (2006); Cobos et al. (2005), in a study of the cost effectiveness of a CDSS for the management of hypercholesterolemia; pointed out the lack of agreements with the system created an impediment to use. Subramanian et al. (2007), in their physician order entry system using CDSS, included the loss of productivity of the clinician as a barrier to use of the system.

\subsubsection{Performance Expectancy Facilitators to CDSS Adoption in Clinical Practice}

Performance expectancy facilitators were the most common noted among the articles reviewed by the authors. Facilitators perceived to enhance individual performance in practice were most often cited as reasons to use the CDSS in a clinical setting. Bullard et al. (2008), assessing the sensibility of two CDSS, and Subramanian et al. (2007), included the chance of decreasing error in clinical practice as a facilitator encouraging clinician use. Bullard et al. (2008) noted applicability to practice and agreed with Egger et al. (2008), in a study of the adoption of anesthesia information management system by academic departments in the U.S., and Subramanian et al. (2007), that the improvement of productivity facilitated use in clinical practice. Integration of the CDSS into the workflow was considered a facilitator in the Leslie et al. (2006) study of CDSS for management of chronic heart failure and the MacLean, Littenberg \& Gagnon (2006) study of diabetes decision support systems. Macy, Skelly, Shiffman \& Flynn (2005); Varonen, Korttesito \& Kaila (2008); Egger et al. (2008); Subramanian et al. (2007); Robertson et al. (2011); Javitt, Rebitzer \& Reisman (2008), in a study of information technology and medical missteps; and Cleveringa et al. (2007), all noted that providing or collecting relevant information for user and patient facilitates the use of CDSS. Proper documentation of procedures facilitated the use of CDSS in clinical practice as noted by Macy, Skelly, Shiffman \& Flynn (2005); Egger et al. (2008); and Subramanian et al. (2007). Potential to improve quality of care was a facilitator among the studies of Toth-Pal, Wardh, Strender \& Nilsson (2008); Egger et al. (2008); Subramanian et al. (2007), Robertson et al. (2011); Glassman, Simon, Belperio \& Lanto (2002), in their study on improving recognition of drug interactions with automated drug alerts; and Wright et al. (2007), in a study of CDSS implementation throughout Wisconsin.

Two other determining facilitators of the use of CDSS in clinical practice were reliability of data and information, as cited by Egger et al. (2008) and Robertson et al. (2011), and integration of the CDSS into the existing computer network systems, as cited by Hor et al. (2010) and MacLean, Littenberg \& Gagnon, (2006). 


\subsection{Effort Expectancy}

The UTAUT model defines effort expectancy as the "degree of ease associated with the use of the system" (Venkatesh, Morris, Davis \& Davis, 2003). Among the literature reviewed, multiple barriers and facilitators were identified, which indicated the practitioners' perceptions regarding the ease of using the CDSS and the items which eased or hindered its use in clinical practice.

\subsubsection{Effort Expectancy Barriers to CDSS Adoption in Clinical Practice}

Seven definitive determinants classified within the UTAUT model were cited as barriers to CDSS use in clinical practice. Leslie et al. (2006); Harrison et al. (2009), a study of implementing patient decision support tools within surgical consultation for patients with rectal cancer; and Murray et al. (2004) all noted the complexity of a system would hinder its use by practitioners. The lack of knowledge of a system or its content created a barrier in the studies of Trafton et al. (2010); Peek et al. (2011); Wright et al. (2007); Robertson et al. (2011); Glassman, Simon, Belperio \&Lanto (2002); and Lai, Macmillan, Daudelin \& Kent (2006). The user or physician's attitude towards the system became an apparent barrier in the studies of Toth-Pal, Wardh, Strender \& Nilsson (2008); Peek et al. (2011); Varonen, Korttesito \& Kaila (2008); and Wright et al. (2007). Varonen, Korttesito \& Kaila (2008); Robertson et al. (2011); and Murray et al. (2004) cited a barrier when the systems to be implemented were less user-friendly and impeded their implementation into clinical practice. Other barriers of note included too many unwanted alerts cited by Robertson et al. (2011); Glassman, Simon, Belperio \& Lanto (2002); Tierney et al. (2005); and Murray et al. (2004). Poor system design was noted by Hor et al. (2010) and Robertson et al. (2011). Hor et al. (2010) also noted the lack of flexibility within the system acted as a barrier to clinical implementation.

\subsubsection{Effort Expectancy Facilitators to CDSS Adoption in Clinical Practice}

A facilitator, as defined by the UTAUT model on effort expectancy, should be perceived as accommodating to the user. Good information presentation was cited as a facilitator by Bullard et al. (2008); Macy, Skelly, Shiffman \& Flynn (2005); and Robertson et al. (2011). Other facilitators included user-friendliness, cited by Bullard et al. (2008); Varonen, Korttesito \& Kaila (2008); and Robertson et al. (2011), and usability testing, cited by Bullard et al. (2008); Tierney et al. (2005); and Trafton et al. (2010). Another significant facilitator was the ease of finding information within the CDSS which is patient or user relevant; this factor was cited among the works of Bullard et al. (2008), Robertson et al. (2011), and Trafton et al. (2010). Significant facilitation in implementation was discovered when a system had fast information retrieval and transfer in the studies of Subramanian et al. (2007); Hor et al. (2010); Wilson \& Opolski (2009); and MacLean, Littenberg \& Gagnon, (2006). Good system design facilitated use in the studies of Javitt, Rebitzer \& Reisman (2008) and Wilson \& Opolski (2009). Toth-Pal, Wardh, Strender \& Nilsson (2008); Varonen, Korttesito \& Kaila (2008); Murray et al. (2004); and Derose et al. (2005) credited the flexibility of the system as a facilitator to use by practitioners in clinical practice. Peek et al. (2011) considered reducing complexity as a facilitator to use of a cardiac decision support system within an electronic health record in clinical practice.

\subsection{Social Influence}

The UTAUT model considers social influence as how the individual perceives others will view them as a result of using the technology (Venkatesh, Morris, Davis \& Davis, 2003). This area provided the least amount of identifiable barriers and facilitators among the studies we reviewed.

\subsubsection{Social Influence Barriers to CDSS Adoption in Clinical Practice}

The most significant social influence barrier of note was the reluctance to use the system in front of patients. This observation was noted in the studies of Leslie et al. (2006); Macy, Skelly, Shiffman \& Flynn (2005); Toth-Pal, Wardh, Strender \& Nilsson (2008); Varonenet al. (2008); and Harrison et al. (2009). It was not clearly defined if the negative perception of the patient was determined by the practitioner's ability to use the system, or the perception that the practitioner used the system due to a gap in knowledge of the practitioner. In addition to negative perceptions, cultural concerns worked as a barrier in the study of Kazemi et al. (2009). Their study of the physician's opinion in the current prescription process and the perceived benefits and obstacles of employing a CDSS noted cultural concerns which influenced the physician's opinions. Kazemi et al. (2009) and Lai, Macmillan, Daudelin \& Kent (2006), also noted social barriers and a lack of social acceptance as barriers to the use of CDSS in clinical practice settings. 


\subsubsection{Social Influence Facilitators to CDSS Adoption in Clinical Practic}

Social influence facilitators of note were the discrete accessibility of resources cited by Robertson et al. (2011). The ability of practitioners to access the system unbeknownst to the patient facilitated usage by the practitioner. An individual's positive user attitude was also noted as facilitating a CDSS implementation into practice in the studies of Kazemi et al. (2009), Wright et al. (2007), Egger et al. (2008), and Hor et al. (2010).

\subsection{Facilitating Conditions}

The UTAUT model considers facilitating conditions to be the degree to which an individual believes the organizational and technical infrastructure exist to support the use of the CDSS (Venkatesh, Morris, Davis \& Davis, 2003). Barriers and facilitators are evident within the individual, as well as the organization using the CDSS.

\subsubsection{Facilitating Conditions Barriers to CDSS Adoption in Clinical Practice}

Eight unique facilitating conditions barriers were found among the literature review. This determinant was found to have the most barriers to implementation in clinical practice of CDSS systems. Poor computer skills was cited in the studies of Leslie et al. (2006) and Toth-Pal, Wardh, Strender \& Nilsson (2008) as inhibiting use in clinical practice. Economic constraints and finances and resources were the most prevailing facilitating conditions barriers to successful implementation of a CDSS system cited in the research of Kazemi et al. (2009); Macy, Skelly, Shiffman \& Flynn (2005); Egger et al. (2008); Peek et al. (2011); Subramanian et al. (2007); Robertson et al. (2011); and Cobos et al. (2005). Provider discontinuity and/or support created a barrier for Egger et al. (2008) and Trafton et al. (2010). Trafton et al. (2010) also noted that poor customer support hindered the effective use of the system for evidenced based automation. The studies of Varonen, Korttesito \& Kaila (2008); Peek et al. (2011); and Coboset al. (2005) noted that a clinician with a prior bad experience in the use of CDSS can be considered a barrier to its use. Lack of motivation or incentives created a barrier among the studies of Peek et al. (2011) and Hor et al. (2010). Lack of training on the system was a barrier cited in Hor et al. (2010). Lai, Macmillan, Daudelin \& Kent (2006) and Hor et al. (2010) cited a lack of the awareness existence was a facilitating condition barrier in their studies.

\subsubsection{Facilitating Conditions Facilitators to CDSS Adoption in Clinical Practice}

A unique set of facilitators of note in the Leslie et al. (2006) research on CDSS in chronic heart failure was computer literacy of younger generation and good computer skills. This set of facilitators may indicate future generations and future research may have greater acceptance of CDSS, simply due to familiarity with technology. Enhancing user/provider knowledge was cited by Trafton et al. (2010) as a facilitating condition for CDSS usage. The facilitator of economic incentives to user or provider when using a system was cited in the articles of Wilson \& Opolski (2009); Subramanian et al. (2007); and MacLean, Littenberg \& Gagnon (2006). In the research of Wilson \& Opolski (2009), the authors discovered that professional body collaboration and/or endorsement became a unique facilitator indicating a wider acceptance of a CDSS when a professional body endorsed its use or helped to collaborate in the development of the CDSS. Good training was noted as a facilitator to use of the system in the research of Varonen, Korttesito \& Kaila (2008) and Robertson et al. (2011). Good prior experience using a CDSS was cited as a facilitating condition in the work of Peek et al. (2011).

The list of barriers and facilitators identified from the various studies are shown in the table 1 and table 2 respectably below:

Table 1. List of Barriers to CDSS adoption

\begin{tabular}{lcc}
\hline $\begin{array}{l}\text { UTAUT } \\
\text { Model }\end{array}$ & List of Barriers & Papers \\
\hline & & (Trafton, et al., 2010); (Macy, Skelly, Shiffman, \& \\
& Flynn, 2005); \\
Performance & Lack of time/ time constraints & (Toth-Pal, Wardh, Strender, \& Nilsson, 2008); \\
Expectancy & (Peek, et al., 2011); & (Subramanian, et al., 2007); \\
& (Robertson, et al., 2011); & (Harrison, et al., 2009); \\
& (Murray, et al., 2004) \\
\hline
\end{tabular}




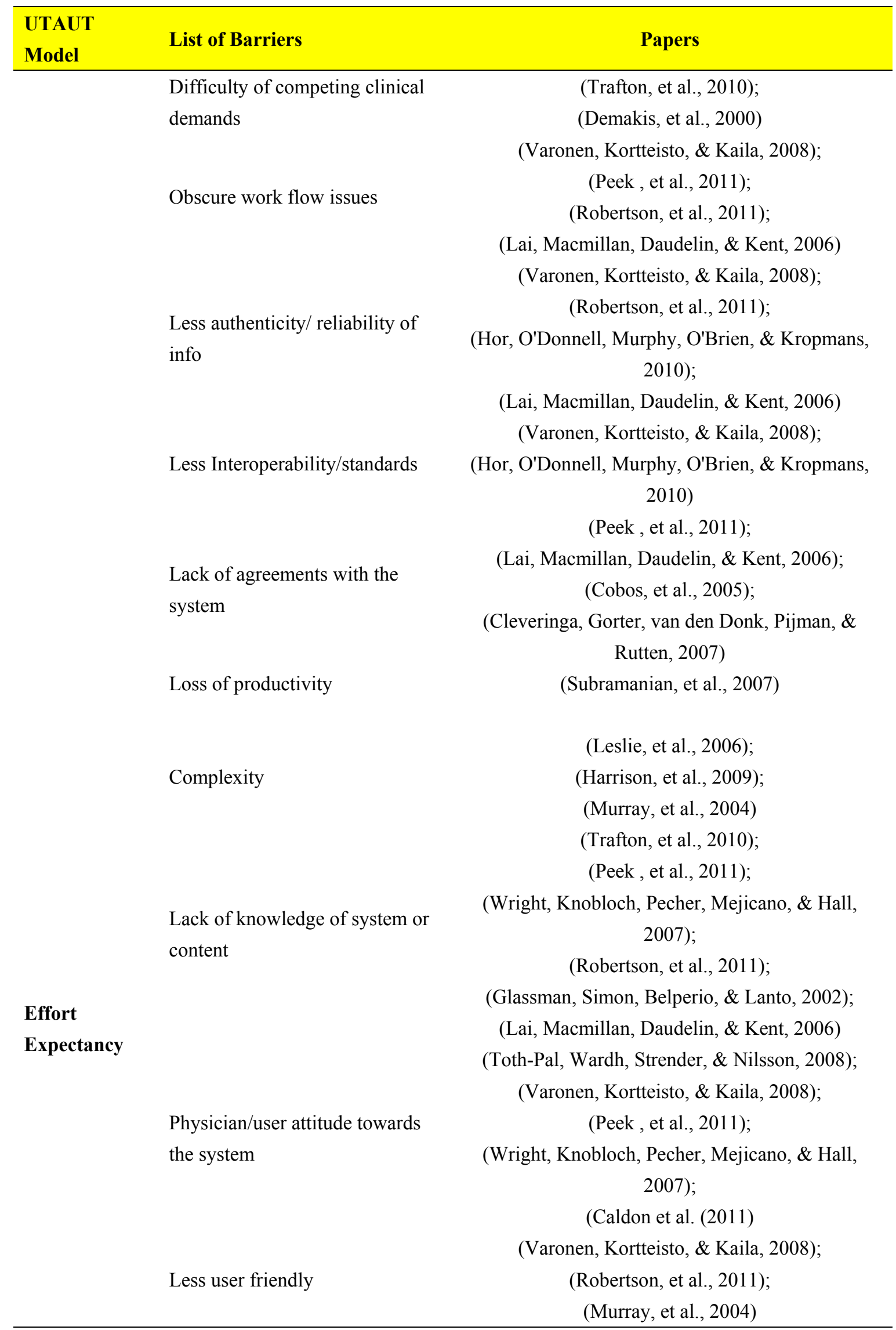




\begin{tabular}{lll}
\hline UTAUT & List of Barriers & Papers \\
Model & & \\
\hline
\end{tabular}

(Robertson, et al., 2011);

Too many unwanted alerts

Poor system design
Lack of flexibility
Reluctance to use system in
front of patients

Social

Influence

Poor computer skills

Economic constraints/ finance and resources

\section{Facilitating \\ Conditions}

Provider discontinuity/support

Poor customer support

Prior bad experience

Lack of motivation/incentives
(Glassman, Simon, Belperio, \& Lanto, 2002);

(Tierney, et al., 2005);

(Murray, et al., 2004)

(Robertson, et al., 2011);

(Hor, O'Donnell, Murphy, O'Brien, \& Kropmans, 2010)

(Hor, O'Donnell, Murphy, O'Brien, \& Kropmans, 2010)

(Leslie, et al., 2006);

(Macy, Skelly, Shiffman, \& Flynn, 2005);

(Wilson \& Opolski, 2009);

(Toth-Pal, Wardh, Strender, \& Nilsson, 2008);

(Varonen, Kortteisto, \& Kaila, 2008);

(Harrison, et al., 2009)

(Kazemi, et al., 2009)

(Kazemi, et al., 2009);

(Lai, Macmillan, Daudelin, \& Kent, 2006)

(Leslie, et al., 2006);

(Toth-Pal, Wardh, Strender, \& Nilsson, 2008)

(Kazemi, et al., 2009);

(Macy, Skelly, Shiffman, \& Flynn, 2005);

(Egger, Epstein, Macario, Pearl, \& Grunwald, 2008);

(Peek , et al., 2011);

(Subramanian, et al., 2007);

(Robertson, et al., 2011);

(Cobos, et al., 2005)

(Trafton, et al., 2010);

(Egger, Epstein, Macario, Pearl, \& Grunwald, 2008)

(Trafton, et al., 2010)

(Varonen, Kortteisto, \& Kaila, 2008);

(Peek , et al., 2011);

(Cobos, et al., 2005)

(Peek, et al., 2011);

(Hor, O'Donnell, Murphy, O'Brien, \& Kropmans, 


\begin{tabular}{lcc}
\hline $\begin{array}{l}\text { UTAUT } \\
\text { Model }\end{array}$ & List of Barriers & Papers \\
\hline & & $2010)$. \\
& Lack of training & (Hor, O'Donnell, Murphy, O'Brien, \& Kropmans, \\
& 2010) \\
& Lack of awareness existence & (Peek, et al., 2011); \\
& (Lai, Macmillan, Daudelin, \& Kent, 2006) \\
\hline
\end{tabular}

Table 2. List of Facilitators to CDSS adoption

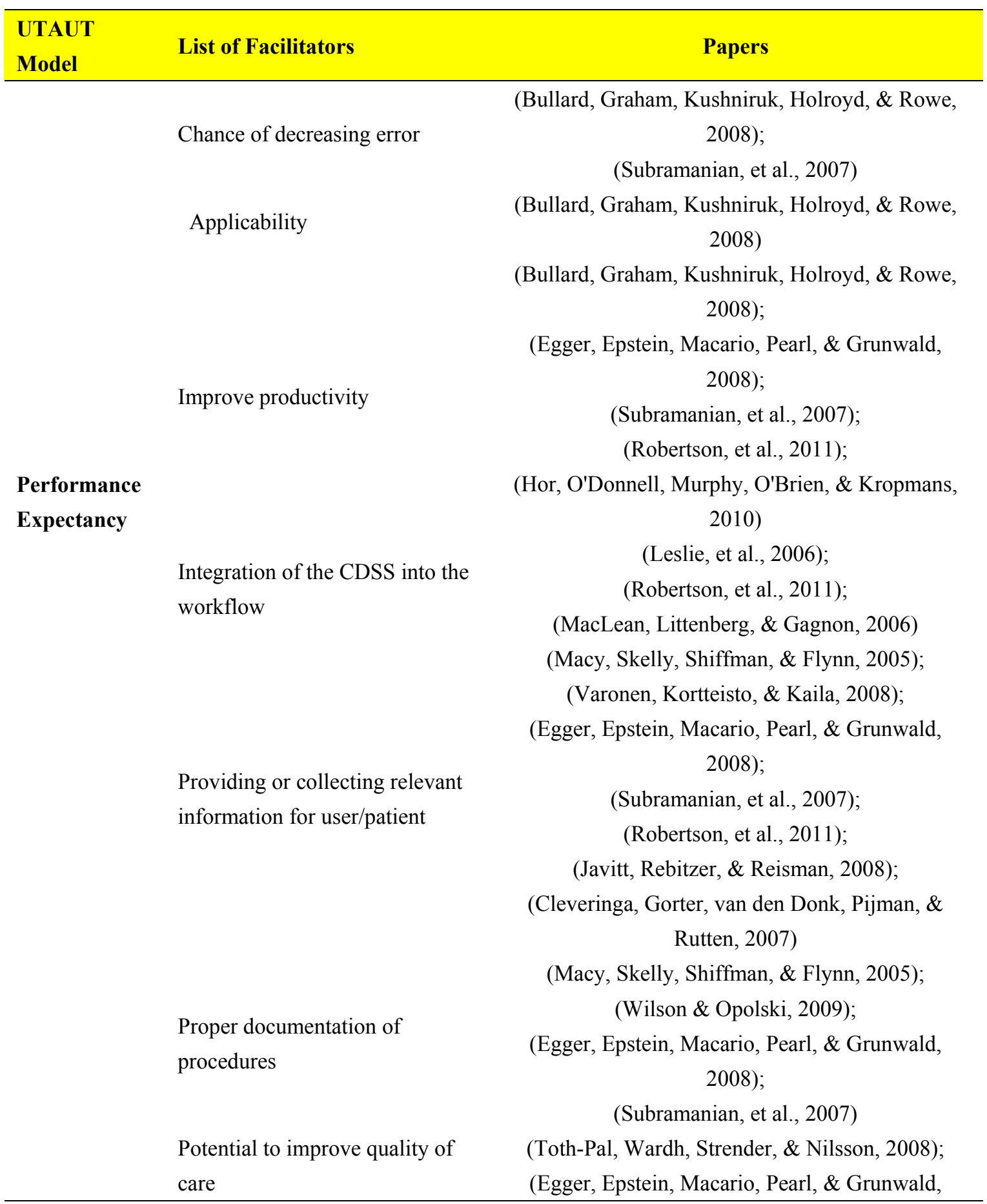




\begin{tabular}{ll}
\hline $\begin{array}{l}\text { UTAUT } \\
\text { Model }\end{array}$ & List of Facilitators \\
\hline & \\
& Reliability of data/information \\
& $\begin{array}{l}\text { Integration of the CDSS into } \\
\text { existing systems }\end{array}$
\end{tabular}

=Effort

Expectancy

\section{Ease of finding information in CDSSs(pt relevant or user} request)

Usability testing

Fast information retrieval/ transfer

Good System Design

Flexibility of system

\section{Papers}

2008);

(Wright, Knobloch, Pecher, Mejicano, \& Hall, 2007);

(Subramanian, et al., 2007);

(Robertson, et al., 2011);

(Glassman, Simon, Belperio, \& Lanto, 2002)

(Egger, Epstein, Macario, Pearl, \& Grunwald, 2008);

(Robertson, et al., 2011)

(Hor, O'Donnell, Murphy, O'Brien, \& Kropmans, 2010);

(MacLean, Littenberg, \& Gagnon, 2006)

(Bullard, Graham, Kushniruk, Holroyd, \& Rowe, 2008);

(Macy, Skelly, Shiffman, \& Flynn, 2005);

(Robertson, et al., 2011)

(Bullard, Graham, Kushniruk, Holroyd, \& Rowe, 2008);

(Varonen, Kortteisto, \& Kaila, 2008);

(Robertson, et al., 2011)

(Bullard, Graham, Kushniruk, Holroyd, \& Rowe, 2008);

(Trafton, et al., 2010);

(Robertson, et al., 2011)

(Bullard, Graham, Kushniruk, Holroyd, \& Rowe, 2008);

(Trafton, et al., 2010);

(Tierney, et al., 2005)

(Wilson \& Opolski, 2009);

(Subramanian, et al., 2007);

(Hor, O'Donnell, Murphy, O'Brien, \& Kropmans, 2010);

(MacLean, Littenberg, \& Gagnon, 2006)

(Wilson \& Opolski, 2009);

(Javitt, Rebitzer, \& Reisman, 2008)

(Toth-Pal, Wardh, Strender, \& Nilsson, 2008);

(Varonen, Kortteisto, \& Kaila, 2008);

(Murray, et al., 2004);

(Derose, et al., 2005) 


\begin{tabular}{|c|c|c|}
\hline $\begin{array}{l}\text { UTAUT } \\
\text { Model }\end{array}$ & List of Facilitators & Papers \\
\hline \multirow{6}{*}{$\begin{array}{l}\text { Social } \\
\text { Influence }\end{array}$} & Reducing complexity & (Peek, et al., 2011) \\
\hline & & (Kazemi, et al., 2009); \\
\hline & & (Egger, Epstein, Macario, Pearl, \& Grunwald, \\
\hline & Positive user attitude & $\begin{array}{l}\text { (Wright, Knobloch, Pecher, Mejicano, \& Hall, } \\
\text { 2007); }\end{array}$ \\
\hline & & $\begin{array}{l}\text { (Hor, O'Donnell, Murphy, O'Brien, \& Kropmans, } \\
\text { 2010) }\end{array}$ \\
\hline & Discrete accessibility of resource & (Robertson, et al., 2011) \\
\hline \multirow{8}{*}{$\begin{array}{l}\text { Facilitating } \\
\text { Conditions }\end{array}$} & $\begin{array}{l}\text { Computer literacy of younger } \\
\text { generation/ good computer skills }\end{array}$ & (Leslie, et al., 2006) \\
\hline & Enhancing user/provider & (Trafton, et al., 2010) \\
\hline & & (Wilson \& Opolski, 2009); \\
\hline & Economic incentives to user or & (Subramanian, et al., 2007); \\
\hline & & (MacLean, Littenberg, \& Gagnon, 2006) \\
\hline & $\begin{array}{l}\text { Professional body } \\
\text { collaboration/endorsement }\end{array}$ & (Wilson \& Opolski, 2009) \\
\hline & Good training & $\begin{array}{l}\text { (Varonen, Kortteisto, \& Kaila, 2008); } \\
\text { (Robertson, et al., 2011) }\end{array}$ \\
\hline & $\begin{array}{l}\text { Good prior experience using } \\
\text { CDSS }\end{array}$ & (Peek, et al., 2011) \\
\hline
\end{tabular}

\section{Discussion \& Summary}

The CDSS acceptance models for barriers and facilitators are shown in figures 2 and 3. These models depend significantly on the UTAUT model. Twenty-one out of the 26 reviewed papers mentioned the specific type of CDSS they are utilizing in the study and these CDSS types are knowledge based. This usage implies that most of the CDSS currently in use in clinical practice are based on rules and associations of compiled data. In these 21 papers, thirteen CDSSs are utilized for patient disease/condition management, 6 are integrated with CPOE, and 2 are employed for diagnostic purposes. This distribution may reflect the areas of utmostneed where physicians warrant assistance in decision making. Furthermore, 7 CDSS are focused on the diagnostic, management, and drug prescription of cardiovascular diseases. Other diseases or conditions cited were diabetes, pneumonia, hypertension, and pain. Please refer to Appendix Table A at the end of the paper for the summary of these findings. 


\section{Performance Expectancy}

- Lack of time/ time constraints

- Difficulty of competing clinical demands

- Obscure work flow issues

- Less authenticity/ reliability of info

- Less Interoperability/standards

- Lack of agreements with the system

- Loss of productivity

\section{Effort Expectancy}

- Complexity

- Lack of knowledge of system or content

- Physician/user attitude towards the system

- Less user friendly

- Too many unwanted alerts

- Poor system design

- Lack of flexibility

\section{Social Influence}

- Reluctance to use system in front of patients

- Cultural concerns

- Social barriers/ lack of social acceptance

\section{Facilitating Conditions}

- Poor computer skills

- Economic constraints - finance and resources

- Provider discontinuity/support

- Poor customer support

- Prior bad experience

- Lack of motivation/ incentives

- Lack of training

- Lack of awareness existence

Figure 2. The CDSS Acceptance Model - Barriers. The rectangles represent the principal determinants from the Unified Theory of Acceptance and Use of Technology (UTAUT) 


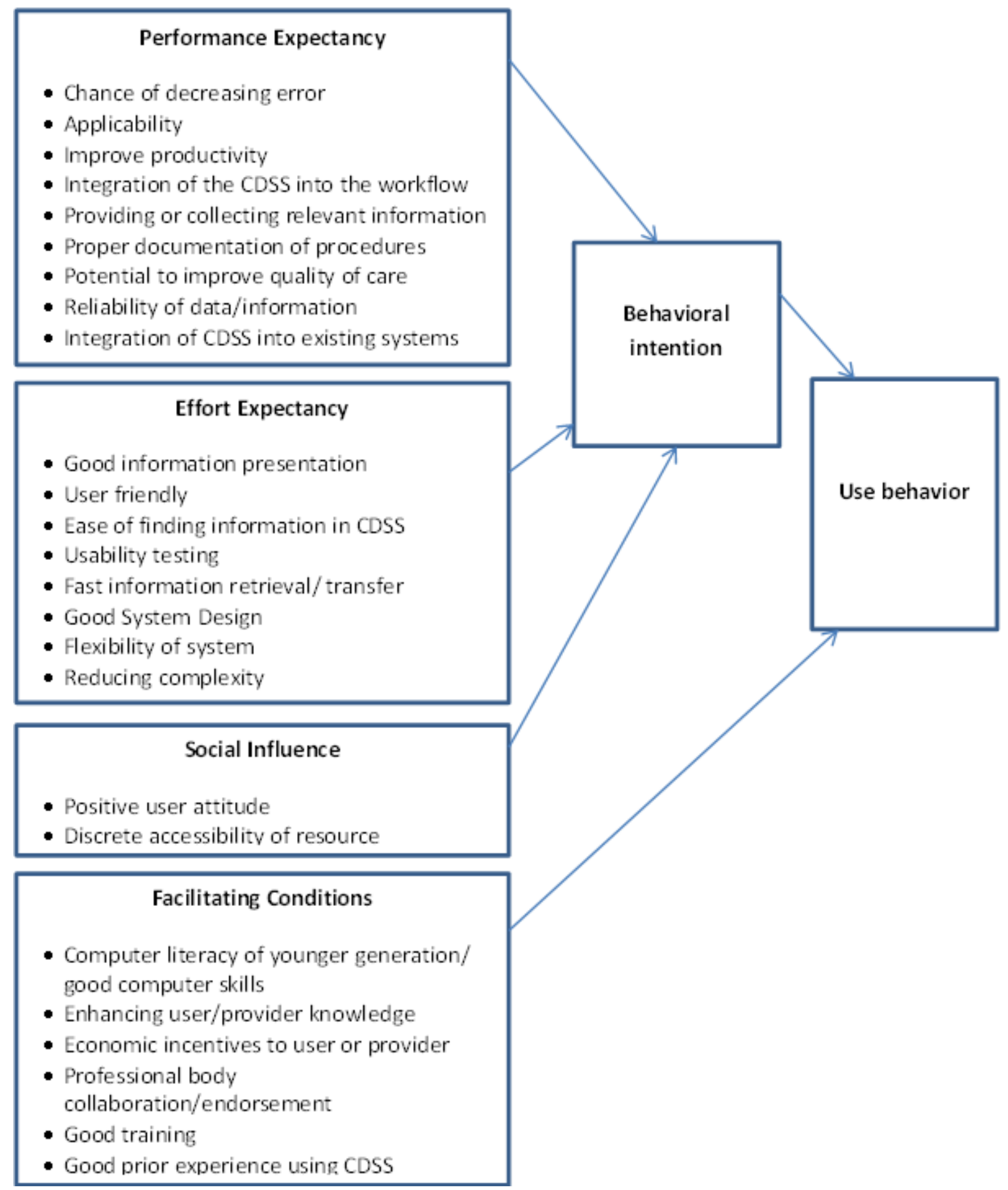

Figure 3. The CDSS Acceptance Model - Facilitators. The rectangles represent the primary determinants from the Unified Theory of Acceptance and Use of Technology (UTAUT)

Table 1 lists the identified barriers to CDSS adoption. Performance expectancy, which is defined as the degree to which an individual believes that using the system will help him or her to attain gains in job performance (Venkatesh, Morris, Davis \& Davis, 2003), had the highest number of cited factors and was followed by effort expectancy, defined as the degree of ease associated with the use of the system; facilitating conditions, defined as the degree to which an individual believes that an organizational and technical infrastructure exists to support use of the system; and social influence, defined as the degree to which an individual perceives that important others believe he or she should use the new system (Venkatesh, Morris, Davis \& Davis, 2003). It should be noted that very little research 
was done in the "social influence" category. More research needs to be done to identify users' subjective norm, social factors, and image while using the CDSS.

Time constraint was the most cited factor for barriers to CDSS adoption, which corresponds to the nature of clinicians' high pressure and fast-pace work environment. This factor was followed by economic constraint, which is probably an evident barrier in many aspects of any technological adoption. Most of the studies also cited clinicians' lack of knowledge of the system and reluctance to use the system in front of patients as obstacles. Table 3 below summarizes these findings.

Table 3. Number of papers citing each barrier

\begin{tabular}{llc}
\hline UTAUT & Barriers & $\begin{array}{c}\text { Number of } \\
\text { papers cited }\end{array}$ \\
\hline Performance Expectancy & Lack of time/ time constraints & 8 \\
Facilitating Conditions & Economic constraints/ finance and resources & 7 \\
Effort Expectancy & Lack of knowledge of system or content & 6 \\
Social Influence & Reluctance to use system in front of patients & 6 \\
Effort Expectancy & Physician/ user attitude towards the system & 5 \\
Performance Expectancy & Obscure work flow issues & 4 \\
Performance Expectancy & Less authenticity/reliability of info & 4 \\
Performance Expectancy & Lack of agreements with the system & 4 \\
Effort Expectancy & Too many unwanted alerts & 4 \\
Effort Expectancy & Complexity & 3 \\
Effort Expectancy & Less user friendly & 3 \\
Facilitating Conditions & Prior bad experience & 3 \\
Performance Expectancy & Difficulty of competing clinical demands & 2 \\
Performance Expectancy & Interoperability/standards & 2 \\
Effort Expectancy & Poor system design & 2 \\
Social Influence & Social barriers/lack of social acceptance & 2 \\
Facilitating Conditions & Poor computer skills & 2 \\
Facilitating Conditions & Provider discontinuity/support & 2 \\
Facilitating Conditions & Lack of motivation/ incentives & 2 \\
Facilitating Conditions & Lack of awareness existence & 1 \\
Performance Expectancy & Loss of productivity & 2 \\
Effort Expectancy & Lack of flexibility & Cultural concerns \\
Social Influence & Poor customer support & 2 \\
Facilitating Conditions & Lack of training & 2 \\
Facilitating Conditions & & 2 \\
\hline & & 2 \\
\hline
\end{tabular}

Table 2 shows the list of facilitators. The most cited factor for facilitating CDSS adoption is that the system provides or collects relevant information for the users (clinicians) as well as patients. This high citation rate may be due to the overwhelming volume of medical, biological, and clinical information which clinicians have to know and analyze. CDSS can be a very helpful tool to support clinicians in this aspect of their profession. Most studies also indicated the CDSS's potential to improve the quality of care and improve productivity, which facilitates system adoption. Table 4 summarizes the number of papers citing each facilitator. 
Table 4. Number of papers citing each facilitator

\begin{tabular}{|c|c|c|}
\hline UTAUT Model & List of Facilitators & $\begin{array}{l}\text { Number of papers } \\
\text { cited }\end{array}$ \\
\hline Performance Expectancy & Providing or collecting relevant information for user/patient & 7 \\
\hline Performance Expectancy & Potential to improve quality of care & 6 \\
\hline Performance Expectancy & Improve productivity & 5 \\
\hline Performance Expectancy & Proper documentation of procedures & 4 \\
\hline Effort Expectancy & Fast information retrieval/ transfer & 4 \\
\hline Effort Expectancy & Flexibility of system & 4 \\
\hline Social Influence & Positive user attitude & 4 \\
\hline Performance Expectancy & Integration of the CDSS into the workflow & 3 \\
\hline Effort Expectancy & Good information presentation & 3 \\
\hline Effort Expectancy & User friendly & 3 \\
\hline Effort Expectancy & Ease of finding information in CDSSs(pt relevant or user request) & 3 \\
\hline Effort Expectancy & Usability testing & 3 \\
\hline Facilitating Conditions & Economic incentives to user or provider & 3 \\
\hline Performance Expectancy & Chance of decreasing error & 2 \\
\hline Performance Expectancy & Reliability of data/information & 2 \\
\hline Performance Expectancy & Integration of the CDSS into existing systems & 2 \\
\hline Effort Expectancy & Good System Design & 2 \\
\hline Facilitating Conditions & Good training & 2 \\
\hline Performance Expectancy & Applicability & 1 \\
\hline Effort Expectancy & Reducing complexity & 1 \\
\hline Social Influence & Discrete accessibility of resource & 1 \\
\hline Facilitating Conditions & Computer literacy of younger generation/good computer skills & 1 \\
\hline Facilitating Conditions & Enhancing user/provider knowledge & 1 \\
\hline Facilitating Conditions & Professional body collaboration/endorsement & 1 \\
\hline Facilitating Conditions & Good prior experience using CDSS & 1 \\
\hline
\end{tabular}

\section{Conclusion}

This systematic qualitative review reveals that improvement in clinical practices using CDSSs will need to address a wide range of factors. The barriers and facilitators which might cause inconsistency with the use of CDSSs are identified in this review. Although some of these barriers are difficult to overcome, the facilitators would increase the user acceptance and therefore the effectiveness of the CDSS. To better assure the successful implementation and management of any CDSS, it is also important to evaluate the user satisfaction. The users would have a positive attitude towards the implementation and use of the CDSS when most of the aforementioned factors are considered while designing the system.

The authors believe the results of systematic review have implications in improving theory and research in the field of CDSSs. The specific use of our results helps in standardizing the factors which influence and target the priorities during the implementation of CDSSs in the future. In this review, some factors were occasionally identified as both a barrier and a facilitator to implementing the CDSS. A comprehensive analysis is required to understand the perceived barriers and facilitators in future qualitative studies.

The benefits of CDSS use will be fulfilled only when the strategies for implementing best practices are known. In order to fulfill this goal of CDSS benefits, it is necessary to identify and evaluate users of healthcare providers who have already implemented a CDSS or will be implementing one in the future. The evaluation method would involve creating an ordinal-scale survey questionnaire based on the barriers and facilitators mentioned in this paper, gather 
the data from users, and then combine the quantitative and qualitative findings in order to form recommendations to increase the efficiency of CDSS. In addition, more studies should be done in assessing social influence factors, especially to identify users' subjective norm, social factors, and image while using the CDSS.

\section{References}

Bullard, M. J., Graham, T. A., Kushniruk, A. W., Holroyd, B. R. \& Rowe, B. H. (2008, October). Assessing the Sensibility of Two Clinical Decision Support Systems. Journal of Medical Systems, 32(5), 361-368. http://dx.doi.org/10.1007/s10916-008-9141-0

Caldon L.J, C. K. (2011). Clinicians' concerns about decision support interventions for patients facing breast cancer surgery options: understanding the challenge of implementing shared decision-making. Health Expect, 133-146. http://dx.doi.org/10.1111/j.1369-7625.2010.00633.x

Cleveringa, F., Gorter, K. J., van den Donk, M., Pijman, P. \& Rutten, G. (2007). Task delegation and computerized decision support reduce coronary heart disease risk factors in type 2 diabetes patients in primary care. Diabetes Technology \& Therapeutics, 9(5), 473-481. http://dx.doi.org/10.1089/dia.2007.0210

Cobos, A., Vilaseca, J., Asenjo, C., Pedro-Botet, J., Sanchez, E., Val, A., . . Bergonon, S. (2005). Cost effectiveness of a clinical decision support system based on the recommendations of the European Society of Cardiology and other societies for the management of hypercholesterolemia: Report of a cluster-randomized trial. Disease Management Health Outcomes, 13(6), 421-432. http://dx.doi.org/10.2165/00115677-200513060-00007

Demakis, J., Beauchamp, C., Cull, W. L., Denwood , R., Eisen, S. A., Lofgren, R. \& Henderson, W. G. (2000). Improving residents' compliance with standards of ambulatory care: results from the VA Cooperative Study on Computerized Reminders. Journal of American Medical Association, 284(11), 1411-1416. http://dx.doi.org/10.1001/jama.284.11.1411

Derose, S. F., Dudl, J. R., Benson, V. M., Contreras, R., Nakahiro, R. K. \& Ziel, F. H. (2005). Point of service reminders for prescribing cardiovascular medications. American Journal of Managed Care, 11(5), 298-304.

East , T., Heermann, L. K., Bradshaw, R. L., Lugo, A., Sailors, R. M., Ershler, L., . . Steinberg , K. (1999). Efficacy of computerized decision support for mechanical ventilation: results of a prospective multi-center randomized trial. Proceedings of AMIA Symposium, (pp. 251-255).

Egger, H. C., Epstein, R. H., Macario, A., Pearl, R. G. \& Grunwald, Z. (2008, October). Adoption of Anesthesia Information Management Systems by Academic Departments in the United States. Anesthesia and Analgesia, 107(4), 1323-1329. http://dx.doi.org/10.1213/ane.0b013e31818322d2

Glassman, P. A., Simon, B., Belperio, P. \& Lanto, A. (2002, December). Improving recognition of drug interactions: benefits and barriers to using automated drug alerts. Medical Care, 40(12), 1161-1171. http://dx.doi.org/10.1097/00005650-200212000-00004

Hales, J. W., Gardner, R. M. \& Jacobson, J. T. (1995). Factors impacting the success of computerized preadmission screening. Annual Symposium on Computer Application in Medical Care, (pp. 728-732).

Harrison, J. D., Masya, L., Butow, P., Solomon, M., Young, J., Salkeld, G. \& Whelan, T. (2009). Implementing patient decision support tools: moving beyond academia? Patient Education and Counseling, 76(1), 120-125. http://dx.doi.org/10.1016/j.pec.2008.12.013

Hetlevik, I., Holmen, J. \& Kruger, O. (1999). Implementing clinical guidelines in the treatment of hypertension in general practice. Evaluation of patient outcome related to implementation of a computer-based clinical decision support system. Scandinavian Journal of Primary Health Care, 17(1), 35-40. http://dx.doi.org/10.1080/028134399750002872

Hor, C. P., O'Donnell, J. M., Murphy, A. W., O'Brien, T. \& Kropmans, T. J. (2010). General practitioners' attitudes and preparedness towards Clinical Decision Support in e-Prescribing (CDS-eP) adoption in the West of Ireland: a cross sectional study. BMC Medical Informatcs \& Decision Making, 10(2). http://dx.doi.org/10.1186/1472-6947-10-2

Javitt, J. C., Rebitzer, J. B. \& Reisman, L. (2008). Information technology and medical missteps: evidence from a randomized trial. Journal of Health Economics, 27(3), 585-602. http://dx.doi.org/10.1016/j.jhealeco.2007.10.008 
Kazemi, A., Ellenius, J., Tofighi, S., Salehi, A., Eghbalian, F. \& Fors, U. G. (2009, March). CPOE in Iran-A viable prospect? Physicians' opinions on using CPOE in an Iranian teaching hospital. International Journal of Medical Informatics, 78(3), 199-207. http://dx.doi.org/10.1016/j.ijmedinf.2008.07.004

Lai, F., Macmillan, J., Daudelin, D. H. \& Kent, D. M. (2006). The potential of training to increase acceptance and use of computerized decision support systems for medical diagnosis. Human Factors, 48(1), 95-108. http://dx.doi.org/10.1518/001872006776412306

Leslie, S. J., Hartswood, M., Meurig, C., McKee, S. P., Slack, R., Procter, R. \& Denvir, M. A. (2006, May). Clinical decision support software for management of chronic heart failure: Development and evaluation. Computers in Biology and Medicine, 36(5), 495-506. http://dx.doi.org/10.1016/j.compbiomed.2005.02.002

MacLean, C. D., Littenberg, B. \& Gagnon, M. (2006). Diabetes decision support: initial experience with the Vermont diabetes information system. American Journal of Public Health, 96(4), 593-595. http://dx.doi.org/10.2105/AJPH.2005.065391

Macy, T. W., Skelly, J., Shiffman, R. N. \& Flynn, B. S. (2005, August). Facilitating adherence to the tobacco use treatment guideline with computer-mediated decision support systems: physician andclinic office manager perspectives. Preventive Medicin, 41(2), 479-487. http://dx.doi.org/10.1016/j.ypmed.2004.11.026

Murray, M. D., Harris, L. E., Overhage, J. M., Zhou, X. H., Eckert, G. J., Smith, F. E. \& Tierney, W. M. (2004). Failure of computerized treatment suggestions to improve health outcomes of outpatients with uncomplicated hypertension: results of a randomized controlled trial. Pharmacotheraphy, 24(3), 324-337. http://dx.doi.org/10.1592/phco.24.4.324.33173

Peek , N., Goud , R., de Keizer, N., van Engen-Verheul, M., Kemps , H. \& Hasman, A. (2011). CARDSS: Development and Evaluation of a Guideline Based Decision Support System for Cardiac Rehabilitation. Artificial Intelligence in Medicine, 6747, 109-118. http://dx.doi.org/10.1007/978-3-642-22218-4_15

Robertson, J. R., Moxey, A. J., Newby, D. A., Gillies, M. B., Williamson, M. \& Pearson, S.-A. (2011, February). Electronic information and clinical decision support for prescribing: state of play in Australian general practice. Family Practice, 28(1), 93-101. http://dx.doi.org/10.1093/fampra/cmq031

Short, D., Frischer, M. \& Bashford, J. (2004). Barriers to the adoption of computerised decision support systems in general practice consultations: a qualitative study of GP's perspectives. International Journal of Medical Informatics, 357-362. http://dx.doi.org/10.1016/j.ijmedinf.2004.02.001

Subramanian, S., Hoover, S., Gilman, B., Field, T. S., Mutter, R. \& Gurwitz, J. H. (2007, September). Computerized physician order entry with clinical decision support in long-term care facilities: costs and benefits to stakeholders. Journal of American Geriatric Society, 55(9), 1451-1457. http://dx.doi.org/10.1111/j.1532-5415.2007.01304.x

Tierney, W. M., Overhage, J., Murray, M. D., Harris, L. E., Zhou, X.-H., Eckert, G. J. \& Wolinksky, F. D. (2005, April). Can computer-generated evidence-based care suggestions enhance evidence-based management of asthma and chronic obstructive pulmonary disease? A randomized, controlled trial. Health Services Research, 40(2), 477-497. http://dx.doi.org/10.1111/j.1475-6773.2005.0t369.x

Toth-Pal, E., Wardh, I., Strender, L.-E. \& Nilsson, G. (2008, March). Implementing a clinical decision-support system in practice: A qualitative analysis of influencing attitudes and characteristics among general practitioners. Informatics for Health \& Social Care, 33(1), 39-54. http://dx.doi.org/10.1080/17538150801956754

Trafton, J., Martins, S., Michel, M., Lewis, E., Wang, D., Combs, A. \& Goldstein, M. K. (2010, April). Evaluation of the Acceptability and Usability of a Decision Support System to Encourage Safe and Effective Use of Opioid Therapy for Chronic, Noncancer Pain by Primary Care Providers. Pain Medicine, 11(4), 575-585. http://dx.doi.org/10.1111/j.1526-4637.2010.00818.x

Varonen, H., Kortteisto, T. \& Kaila, M. (2008, June). What may help or hinder the implementation of computerized decision support systems (CDSSs): a focus group study with physicians. Family Practice, 25(3), 162-167. http://dx.doi.org/10.1093/fampra/cmn020

Venkatesh, V., Morris, M. G., Davis, G. B. \& Davis, F. D. (2003, September). User Acceptance of Information Technology: Toward a Unified View. MIS Quarterly, 27(3), 425-478.

Wilson, A. \& Opolski, M. (2009). Identifying barriers to implementing a cardiovascular computerised decision support system (CDSS): a Delphi survey. Informatics in Primary Care, 17(1), 23-33. 
Wright, M. O., Knobloch, M. J., Pecher, C. A., Mejicano, G. C. \& Hall, M. C. (2007, May). Clinical decision support systems use in Wisconsin. Wisconsin Medical Journal, 106(3), 126-129.

\section{Appendix Table A: Type of CDSS and disease/condition}

\begin{tabular}{|c|c|c|c|c|c|c|c|c|c|}
\hline & \multirow[b]{2}{*}{ Papers } & \multicolumn{3}{|c|}{ Type of CDSS } & \multicolumn{5}{|c|}{ Disease/Condition } \\
\hline & & $\begin{array}{l}\text { Patient disease } \\
\text { management }\end{array}$ & Diagnostic & CPOE & Cardiovascular & Diabetes & Pain & Pneumonia & Hypertension \\
\hline 1 & (Bullard, Graham, Kushniruk, Holroyd, \& Rowe, 2008) & 1 & & & & & & 1 & \\
\hline 2 & (Leslie, et al., 2006); & 1 & & & 1 & & & & \\
\hline 3 & (Kazemi, Ellenius, Totighi, Salehi, Eghbalian, \& Fors, 2009); & & & 1 & & & & & \\
\hline 4 & (Trafton, et al., 2010) & 1 & & & & & 1 & & \\
\hline 5 & (Macy, Skelly, Shiffman, \& Flynn, 2005); & 1 & & & & & & & \\
\hline 6 & (Wilson \& Opolski, 2009) & & 1 & & 1 & & & & \\
\hline 7 & (Toth-Pal, Wardh, Strender, \& Nilsson, 2008); & 1 & & & 1 & & & & \\
\hline 8 & (Varoncn, Korttcisto, \& Kaila, 2008); & & & & & & & & \\
\hline 9 & (Egger, Epstein, Macario, Pearl, \& Grunwald, 2008) & & & & & & & & \\
\hline 10 & $\begin{array}{l}\text { (Peek, Goud, de Keizer, van Engen-Verheul, Kemps , \& } \\
\text { Hasman,2011); }\end{array}$ & 1 & & & 1 & & & & \\
\hline 11 & (Wright, Knobloch, Pecher, Mejicano, \& Hall, 2007); & & & & & & & & \\
\hline 12 & (Subramanian, Hoover, Gilman, Field, Mutter, \& Gurwitz, 2007); & & & 1 & & & & & \\
\hline 13 & (Robertson, Moxey, Newby, Gillies, Williamson, \& Pearson, 2011); & & & 1 & & & & & \\
\hline 14 & (Hor, O'Donnell, Murphy, O'Brien, \& Kropmans, 2010); & & & 1 & & & & & \\
\hline 15 & (Harrison, et al., 2009); & & & & & & & & \\
\hline 16 & (Glassman, Simon, Belperio, \& Lanto, 2002); & & & 1 & & & & & \\
\hline 17 & (Lai, Macmillan, Daudelin, \& Kent, 2006) & & 1 & & 1 & & & & \\
\hline 18 & (Tierney, et al., 2005) & & & 1 & & & & & \\
\hline 19 & (Cobos, et al., 2005); & 1 & & & & & & & \\
\hline 20 & (MacLean, Littenberg, \& Gagnon, 2006) & 1 & & & & 1 & & & \\
\hline 21 & (Murray, et al., 2004); & 1 & & & & & & & 1 \\
\hline 22 & (Demakis, et al., 2000) & 1 & & & & & & & 1 \\
\hline 23 & (Javitt, Rebitzer, \& Reisman, 2008) & & & & & & & & \\
\hline 24 & (Derose, Dudl, Benson, Contreras, Nakahiro, \& Ziel, 2005) & 1 & & & 1 & & & & \\
\hline 25 & (Cleveringa, Gorter, van den Donk, Pijman, \& Rutten, 2007) & 1 & & & 1 & 1 & & & \\
\hline \multirow[t]{2}{*}{26} & (Caldon, et al., 2011) & 1 & & & & & & & \\
\hline & Total & 13 & 2 & 6 & 7 & 2 & 1 & 1 & 2 \\
\hline
\end{tabular}

